\title{
논문 2012-07-23
}

\section{효과적인 다이어트를 위한 모션 게임 기반의 그룹 소셜 다이어트 앱의 개발 \\ (A Group Social Diet Application Based on Motion Game)}

\author{
이 재 원, 이 민 석* \\ (Jaewon Lee, Minsuk Lee)
}

\begin{abstract}
Obesity is one of the biggest problem in modern society. Smartphone could be a good tool to handle this problem. In this paper, we propose a new smartphone app to recommend diet, to offer a physical practice by motion games. Our Android smartphone application encourages friends to join group fitness programs. It interfaces with social network services and smart-TV.
\end{abstract}

Keywords : Fitness, Smartphone application, Motion game, Smart-TV, SNS

\section{I. 서론}

최근 비만 때문에 또는 아름다운 몸매의 유지를 위하여 많은 사람이 다이어트를 하고 있거나 계획 한다. 다이어트의 목적은 '건강을 위해'가 $52.3 \%$, '몸이 무거워 거동이 불편해서'가 $15.0 \%$, '아름다워 보이기 위해서'가 $32.6 \%$ 이었다. 아름다워지기 위한 다이어트는 20 대에서 가장 높았으며 건강을 위한 다이어트는 40 대, 50 대 연령대에서 높았다 [1]. 같 은 연구에서 가장 효과적인 다이어트 방법은 운동 요법(50.2\%), 식사요법(45.0\%), 기타요법(4.8\%) 순 으로 나타났다. 또 다이어트를 위한 운동 회수를 묻 는 질문에 응답자의 $46.5 \%$ 는 '전혀 하지 않는다' 라고 하였으며 대부분의 조사대상자가 운동이 부족 한 것으로 나타났다.

하지만, 다이어트 인구가 이렇게 많음에도 불구 하고 실질적으로 다이어트에 성공한 사례는 그다지 많지 않다. 실패에는 여러 가지 이유가 있을 수 있 겠지만, 결국 어떤 이유에서든 '다이어트를 할 여건 이 안 된다.'라는 것으로 정리해 볼 수 있다. 이러한

* 교신저자(Corresponding Author)

논문접수 : 2012. 02. 26., 수정일: 2012. 04. 10., 채택확정 : 2012. 05. 11.

이민석 : 한성대학교 컴퓨터공학과

이재원 : LG전자 $\mathrm{MC}$ 연구소

※ 본 연구는 한성대학교 교내연구비의 지원으로 이루어졌음.
실패 요인을 효과적으로 제거하기 위하여 만들어진 것이 본 연구에서 제시하는 스마트 폰을 활용한 다 이어트이다.

이 연구에서 개발된 스마트폰 및 스마트 TV 어 플리케이션은 시간적 공간적 제약을 가진 사용자들 의 다이어트 시도를 단순한 운동기록과 먹은 음식 칼로리를 기록하는 다른 기존의 어플리케이션들과 는 달리, 현대인의 생활 패턴을 그대로 담고 있어, 차별화를 된다.

본 연구에서 만들어진 앱은 사용자의 기본 신체 및 생활 패턴 정보와 설정된 목표를 바탕으로 다이 어트를 위한 일일 권장 칼로리 분석을 실시한다. 또 실질적인 모션을 취하여 칼로리 소모를 유도하는 모션 게임, 모두가 공동의 목표를 설정하여 함께 다 이어트를 할 수 있는 그룹 다이어트 시스템, 스마트 $\mathrm{TV}$ 와 연동한 운동 등을 제공함으로써 성공적으로 다이어트 목표를 달성할 수 있도록 돕는다.

본 논문의 II 장에서는 여러 다이어트 관련 앱들 의 동작과 한계에 관하여 조사하고, III 장에서는 본 연구에서 구현한 다이어트 앱에 대하여 기술한다. IV 장에서는 연구 결과를 요약하고 향후 연구 진행 방향을 제시한다.

\section{II. 다이어트 앱}

다이어트 산업은 가장 큰 건강 산업 가운데 하 나로, 스마트폰이 나오면서, 다양한 형태의 앱이 등 


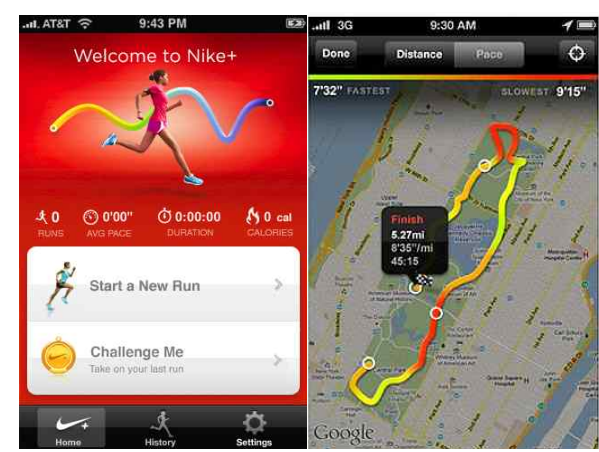

그림 1. 달리기 운동 기능을 강조한 Nike + GPS

Fig. 1. Nike+ GPS

장하였다. 대표적인 다이어트 앱은 음식의 칼로리를 쉽게 확인할 수 있도록 하여 스스로 음식 섭취를 조절할 수 있도록 도와주는 앱, 운동을 유도하고 운 동의 효과를 다양한 형태로 보여주는 앱 등이 있다. 본 연구에서는 운동 방법을 제시함과 동시에 모션 센서를 이용하여 운동 여부를 측정하며, 그룹으로 목표를 설정하여 다이어트를 할 수 있도록 하여 다 이어트에 관한 의지가 유지될 수 있도록 하였다.

이 장에서는 우리 연구에서 참고했던 기존 스마 트폰 앱들을 살펴본다.

\section{1. 나이키+ GPS (Nike+ GPS)}

운동구 전문 업체 나이키 (Nike) 사에서 제공하 는 Nike+ GPS[2](그림 1)는 우리에게 가장 잘 알 려져 있는 아이폰 앱 중 하나이다. 간단한 UI와 사 용법으로 자신이 달리기를 한 결과와 정보를 상세 하게 알 수 있으며, 웹과 연동이 가능해 자신의 목 표와 운동내용을 정리하며 계획을 세울 수 있다는 것이 장점이다. 또한, 신발에 부착된 센서와 스마트 폰에 내장된 $\mathrm{GPS}$ 를 이용하여 달리기를 한 시간과 거리, 궤적을 상당히 정확하게 관리할 수 있다 [3].

\section{2. 카디오 트레이너 (Cardio Trainer)}

안드로이드 Health/Fitness 카테고리의 상위권 을 차지하고 있는 워크스마트 (Worksmart) 사의 Cardio Trainer [4](그림 2)는 통합 운동 앱이다. Cardio Trainer는 기본 어플리케이션인 Cardio Trainer와 함께 응용 프로그램의 플러그인 (Plug-in) 형태의 추가 앱을 통하여 다이어트 관련 확장 기능을 제공한다. 예를 들어, '눔 (Noom) 다이 어트’라는 칼로리 관리 전용 앱과 블루투스와 연동

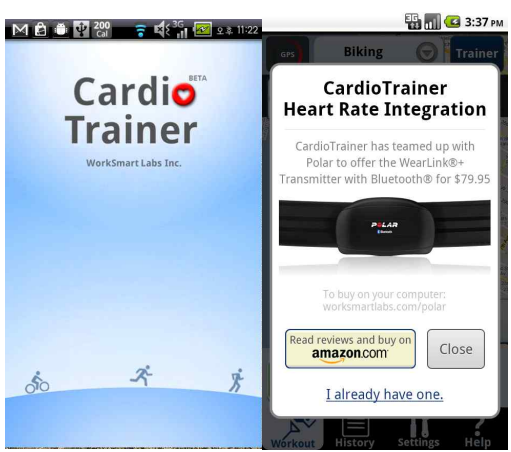

그림 2. 카디오 트레이너

Fig. 2. Cardio Trainer

가능한 심박 수 관리 기능 등을 제공한다.

\section{3. 다이어트 파트너 (Diet Partner)}

모바일 킹 (MobileKing) 사의 Diet Partner [5](그림 3) 앱은 주로 여성들을 겨냥한 UI와 세밀 한 칼로리 관리로 성공한 대표적인 아이폰 앱이다. 실질적으로 다이어트를 위한 방법 자체는 제시하고 있지 않으나 칼로리에 대한 방대한 데이터를 제공 해주고 관리해주며 앱을 사용하는 사용자는 간단한 조작만 통하면 오늘 내가 섭취하고 소모한 칼로리 를 한 눈에 알아 볼 수 있게 된다.

\section{4. 본 연구의 차별성}

본 연구를 통하여 개발된 앱, SomeBody는 기존 다이어트 앱들이 통상적으로 제공하고 있는 칼로리 관리뿐만 아니라, 모션 센서를 이용한 운동 관리기
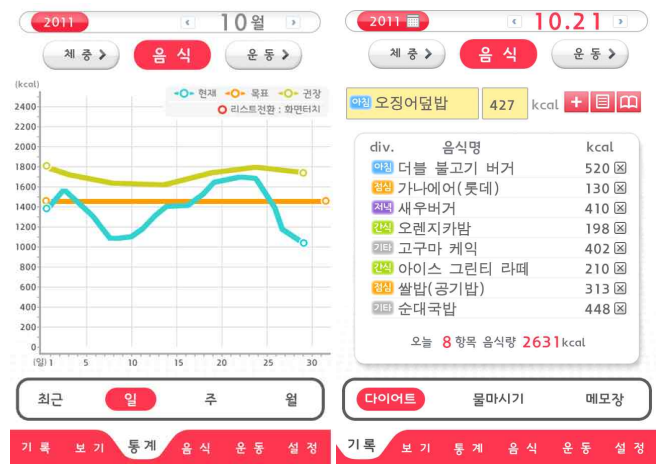

그림 3. 다이어트 파트너

Fig. 3. Diet Partner 


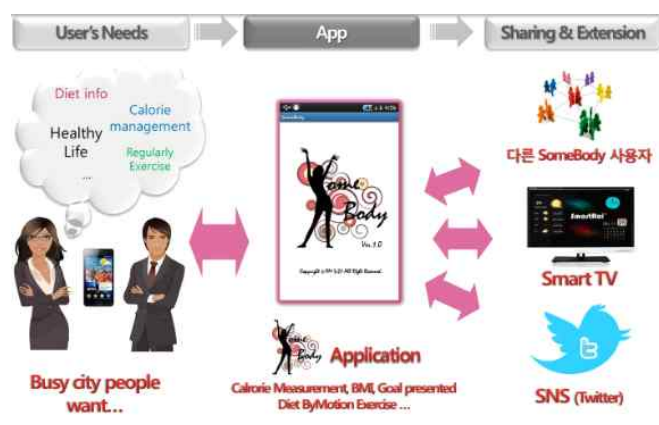

그림 4. SomeBody 실행 환경

Fig. 4. Fitness Application, SomeBody

능을 포함하고 있다. 또한, 그룹 단위의 관리 방식 을 제공하여 사용자들의 동기를 유발함으로써 다이 어트에 효과적이다. 또 스마트폰과 스마트 TV를 통 하여 운동을 유도한다. SomeBody는 스마트폰의 모 션 센서를 이용하여 운동을 감지하고, 운동량을 칼 로리로 변환하는 등, 좀 더 정확한 칼로리 섭취 및 소모를 계산함으로써 기존 다이어트 앱과는 그 기 능이 차별된다.

다이어트는 실행 의지가 매우 중요한데, SomeBody는 그룹 단위의 관리, SNS를 통한 실적 포스팅 등으로 다이어트 및 운동을 지속할 수 있도 록 유도한다.

\section{III. 구현}

본 연구에서 개발된 다이어트 앱은 스마트폰, 서 버, 스마트 TV가 연동되어 실행된다. 앱은 칼로리 계산에 의한 영양 섭취 및 운동 예시 및 따라하기, 그룹 다이어트에 의한 성과 관리 기능을 제공한다. 구현된 SomeBody 다이어트 앱의 실행 환경은 그 림 4 와 같다.

이 장에서는 연구에서 구현된 다이어트 앱인 SomeBody를 소개하고 각 부분의 구현 내용에 대 하여 설명한다.

\section{SomeBody 구현 결과}

스마트폰에서의 구현은 안드로이드 스마트폰 환 경에서 이루어졌으며, 스마트 TV는 구글 $\mathrm{TV}$ 플랫 폼을 이용하였다. 그림 5는 스마트폰에 구현된 결과 물을 보여주고 있다. 그림5의 왼쪽 위 그림은 사용 자의 기초 정보 입력, 오른쪽 위는 모션 게임 메뉴, 그림 5 의 왼쪽 아래 그림은 다이어트 결과를 트위 터, 페이스북으로 보내는 SNS 연동 화면, 오른쪽

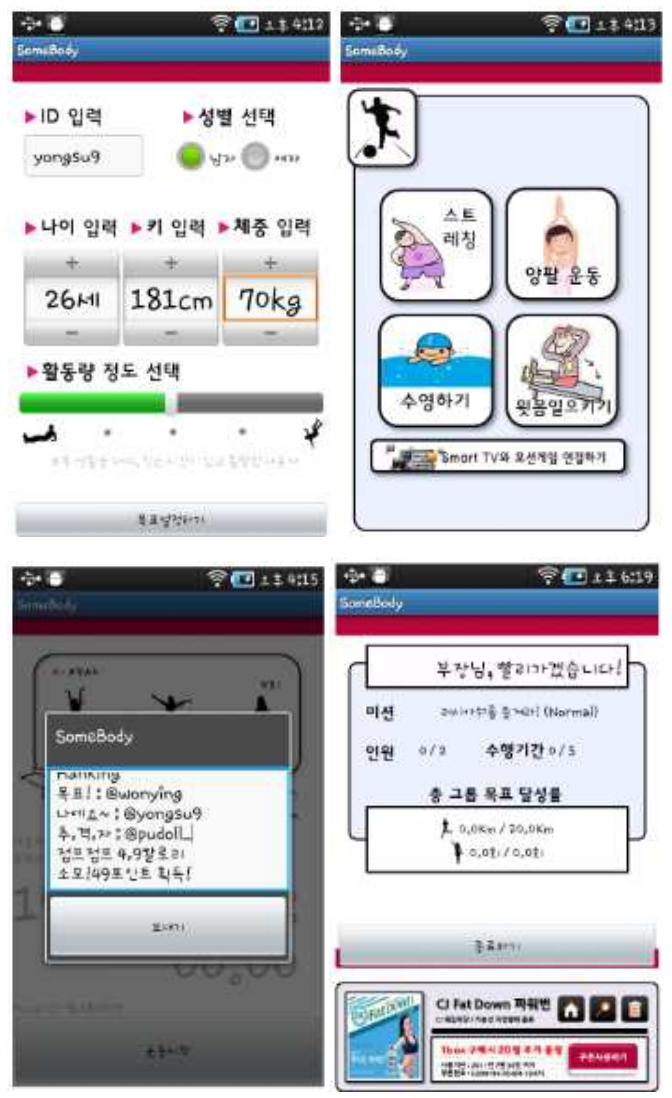

그림 5. 구현된 다이어트 앱, SomeBody

Fig. 5. Screenshot of SomeBody

아래는 그룹 다이어트 화면을 보이고 있다.

\section{2. 칼로리 분석 알고리즘}

사용자의 현재 신체 상태에 따른 칼로리를 산출 하기 위해, 본 연구에서 사용된 칼로리 분석 알고리 즘은 관련 연구에서 가장 많이 인용되는 방법인 Harris Benedict의 기초 대사량 (BMR, Basal Metabolic Rate) 산정 공식 (HBE, Harris Benedict Equation)이다 [6]. 이 공식의 남성과 여 성의 기초 대사량을 계산 방법은 다음과 같다.

$\operatorname{BMR}($ 남자 $)=66.5+(13.75 * m)+(5.003 * h)-\left(6.755^{*}\right.$ a $)$ $\mathrm{BMR}($ 여자 $)=655.1+\left(9.563^{\star} m\right)+\left(1.850^{\star} h\right)-\left(4.676^{\star} a\right)$ (여기서, $\mathrm{m}:$ 체중 $(\mathrm{kg}), \mathrm{h}:$ 키 $(\mathrm{cm}), \mathrm{a}:$ 나이)

본 연구에서도 이 공식을 사용하여 다이어트를 위한 권장섭취량을 결정하며, [7]에 제시된 바와 같 
표 1. 일일 권장 섭취 칼로리

Table 1. Recommended Daily Calories

\begin{tabular}{|l|l|}
\hline \multicolumn{1}{|c|}{ 운동량 } & \multicolumn{1}{c|}{ 권장 칼로리 } \\
\hline 운동 안 함 & BMR $\times 1.2$ \\
\hline 주당 $1 \sim 3$ 일 & BMR $\times 1.375$ \\
\hline 주당 3 5일 & BMR $\times 1.55$ \\
\hline 주당 $6 \sim 7$ 일 & BMR $\times 1.725$ \\
\hline 하루에 2회 이상 & BMR $\times 1.9$ \\
\hline
\end{tabular}

이 활동량에 따라 일일 필요 칼로리(즉, 권장 칼로 리)를 표 1 과 같이 계산해 낼 수 있다.

이렇게 계산된 일일 권장 섭취량에 다이어트 기 간을 곱하게 되면, 현재 체중을 기준으로 해당 기간 동안의 총 권장 섭취량을 얻을 수 있다. 이 권장 섭 취량은 현재 체중을 계속 유지하기 위한 섭취량이 므로, 다이어트를 위해서 줄이고 싶은 체중을 $\mathrm{C}$ 라 고 하면

\section{$C=$ 현재 체중 $(\mathrm{Kg})-$ 목표 체중 $(\mathrm{Kg})$}

이고, 체중 $1 \mathrm{Kg}$ 를 감량해야 할 때 소비되어야 하 는 체지방 기준 칼로리는 다음과 같이 계산할 수 있다. 식에서 $7,200 \mathrm{Kcal}$ 는 지방 $1 \mathrm{Kg}$ 에 대한 등가 열량이다.

$$
\text { 총 소비 칼로리 }=C(\mathrm{Kg}) \text { *7,200 }(\mathrm{Kcal} / \mathrm{Kg})
$$

앱에서는 총 소비 칼로리를 목표 다이어트 기간 으로 나눈 일일 감량 칼로리를 구해서 다음과 같은 방법으로 다이어트 기간 중 총 섭취 칼로리를 구하 였다.

\section{다이어트용 총 섭취 칼로리 $(\mathrm{Kcal})=$}

(일일권장칼로리 - 일일감량칼로리) * 기간

이 다이어트용 총 섭취 칼로리는 목표 다이어트 기간 동안 원하는 몸무게에 이르기 위해 섭취해야 하는 칼로리로서 기본 활동을 제외한 추가적인 운 동을 하지 않는 경우의 섭취량을 의미한다. 추가적 인 운동을 하는 경우, 그 운동이 소비하는 만큼의 추가적인 칼로리 섭취가 가능하다.

본 연구의 앱은 이 칼로리 계산과 운동량을 바 탕으로 운동 목표, 음식 섭취에 대한 목표 칼로리를 계산한다.

\section{3. 센서를 활용한 모션인식}

본 연구에서는 사용자가 지속적으로 다이어트를 할 수 있는 환경을 위해 몸을 움직이면서 할 수 있는 그림

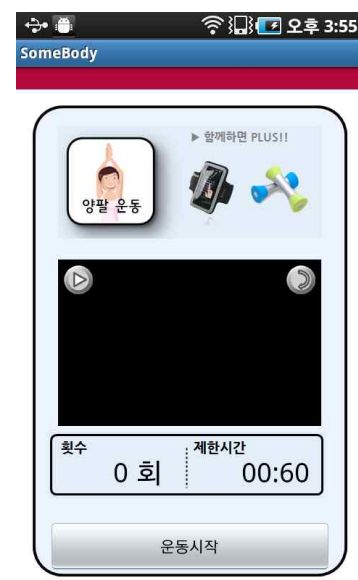

그림 6. 모션 게임

Fig. 6. Motion Game

6 과 같은 모션 게임들을 구현하였다. 모션 게임은 단말 기에 내장된 가속도 센서와 근접 센서를 활용하였다. 구 체적으로 센서의 구동은 안드로이드의 SensorManager 를 이용하였다.

현재 구현된 모션 게임은 [8]의 시뮬레이터를 이용 하여 구현된 뒤, 개발된 앱의 실행 환경인 안드로이드 플랫폼에 이식되었다. 화면상에서 동작 예시를 보여주 고, 사용자가 스마트폰을 들고 팔을 위, 아래로 움직이 는 운동을 $\mathrm{Y}$ 축 가속계를 이용하여 감지하고 운동 결과 를 계산하는 알고리즘에 따라 소모된 칼로리를 산출한 다. 구현된 게임은 네 가지로 스트레칭, 양팔 운동, 수 영하기, 윗몸 일으키기이다.

운동에 의해 소모된 칼로리 계산은 [9]에서 제시된 운동량에 따른 칼로리 등가치 (METS, Metabolic Equivalents) 값과 계산식을 활용하였다. [9]에서는 다 음과 같은 식에 의해 운동에 의해 소모된 칼로리를 계 산한다.

\section{분당 칼로리 소모량 $=0.0175 \times$ MET $\times \mathrm{m} \times \mathrm{t}$}

식에서 MET는 [9]에 제시된 각 운동별 기준값, $\mathrm{m}$ 은 몸무게 $(\mathrm{Kg}), \mathrm{t}$ 는 운동 시간(분)이다. 본 연구에서는 센서로 인식하도록 구현된 모션들인 스트레칭, 양팔 운 동, 수영, 윗몸 일으키기 동작에 대하여 각각 $1.0,1.0$, $3.0,3.0$ 의 MET 값을 적용하여 운동에 의해 소모된 칼 로리를 계산하였다.

\section{4. 그룹 다이어트}

본 연구에서는 사용자들이 다이어트의 목표를 성공적으로 달성할 수 있도록 그룹 다이어트 방식 


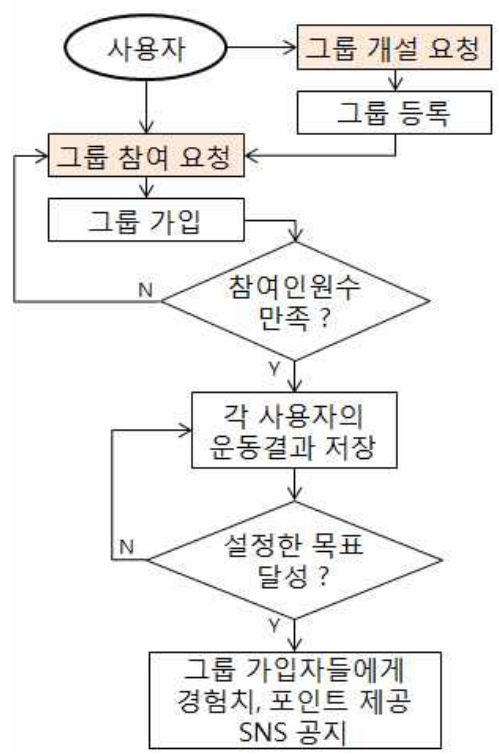

그림 7. 그룹 다이어트의 서비스 흐름도

Fig. 7. Flowchart for Group Fitness

을 제안하였다. 즉, 사용자들에게 그룹 공동의 목표 를 함께 달성하도록 유도하는 기능을 제공함으로서 각 사용자가 책임감을 가지고 다이어트를 지속할 수 있도록 한다. 구현된 그룹 다이어트 서비스의 시 스템은 그림 7 과 같이 동작한다. 이 앱은 서버에 그 룹별 모임 공간을 유지하고, 앱 사용자들은 그 그룹 에 가입하여 그룹별 다이어트 목표를 설정한 뒤, 다 이어트 활동을 수행한다. 다른 활동들과 같이 사용 자의 그룹 다이어트 활동은 다른 그룹 멤버는 물론 소셜 네트워크 서비스를 통해 전파되기 때문에 다 이어트에 관한 의지를 멤버들 사이에 지속적으로 유지할 수 있는 동력을 준다.

사용자가 앱에서 그룹을 생성하거나 생성된 그룹 에 참여 요청을 하면 서버가 요청을 받아 처리하게 되고 그룹 설정에서 정한 수의 인원이 참여하게 되면 그룹 다이어트가 시작된다. 그 이후 설정된 다이어트 목표에 따라 각 사용자가 운동을 하면 서버에서 그룹 별로 운동량을 관리한다. 그룹에서 목표했던 운동량이 만족되면 그룹 다이어트가 성공적으로 종료되고 참여 한 사용자에게 경험치 및 포인트를 분배한다.

\section{5. 스마트 TV 연동}

스마트폰에서 제공하는 모션 게임은 모션 센서 를 이용하기 때문에 사용자는 단말기를 손에 들고

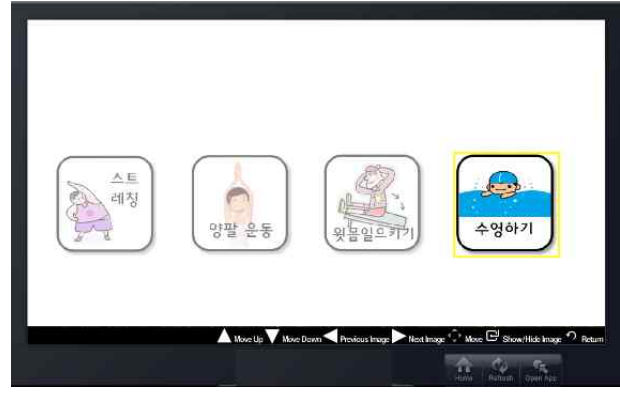

그림 8. 스마트 $\mathrm{TV}$ 앱

Fig. 8. Smart TV Application

운동을 해야 한다. 즉, 화면의 동작을 보면서 운동 을 할 수는 없다. 따라서 보면서 하는 게임보다 상 대적으로 흥미가 떨어진다. 이점을 보안하기 위해서 본 연구에서는 그림 8 에서 보는 것과 같은 스마트 $\mathrm{TV}$ 어플리케이션도 구현하여 연동하였다.

메뉴에서 게임을 선택하면 화면에서 애니메이션 으로 운동 동작이 플레이되며, 스마트폰을 손에 들 고 있는 사용자는 그 동작을 따라하게 된다. 스마트 $\mathrm{TV}$ 는 $\mathrm{WiFi}$ 통신으로 스마트폰과 연결되며, 스마트 폰에서 측정된 센서 값을 $\mathrm{TCP} / \mathrm{IP}$ 소켓 통신 방식 으로 스마트 TV로 넘겨준다. 스마트 TV의 어플리 케이션은 센서 값을 처리하여 사용자의 움직임을 모션 게임에 반영하게 된다.

구현에 사용된 스마트 TV는 구글 TV 플랫폼을 사용하였으며, 현재까지는 가속도 센서 및 근접 센 서만을 사용하여 움직임을 감지하기 때문에 스마트 폰에서와 같이 그림 8 에서와 같은 비교적 간단한 동작의 운동만 가능하다.

\section{IV. 결론 및 향후 연구}

현재 애플 앱스토어 및 안드로이드 마켓의 Health/Fitness 카테고리의 상위권에 있는 어플리케 이션은 주로 칼로리 관리, 다이어트에 도움이 되는 앱 들이다. 하지만 대부분 다이어트 앱들은 사용자의 수 동적인 입력을 바탕으로 관리할 수 있는 데이터를 주 는 역할을 하고 있기 때문에 실질적으로 다이어트 효 과를 얻기는 어렵다.

하지만 사용자들은 지금의 서비스 보다 좀 더 지 능적이고 실질적인 도움을 줄 수 있는 서비스를 원한 다. 본 연구에서 개발된 앱은 장소 제약 없이 사용자 가 측정 가능한 운동을 할 수 있도록 모션 센서를 이 용한 게임을 제공하여 운동량을 측정하고 그 결과를 바탕으로 칼로리를 관리해 준다. 또 이 앱은 그룹 별 
로 다이어트 목표를 관리할 수 있고, 다이어트 진행과 정 및 성과를 트위터와 같은 소셜 네트워크 서비스와 연동할 수 있어 다이어트 의지를 유지하여 목표를 달 성할 수 있도록 한다. 또, 스마트 TV를 이용하여 운 동 효과를 늘릴 수 있도록 지원하고 있다.

앞으로 모션 센서를 더 정확하게 감지하고 분석하 여 다양한 움직임으로 가진 운동을 제시하고 그 실행 여부를 확인할 수 있는 연구가 필요하다. 이 과정에서 본 연구에서는 사용하지 않고 있는 자이로 센서를 3 축 가속도 센서와 결합하여 분석하는 과정이 필요하 다. 다른 방법으로는 고정형 장치인 스마트 $\mathrm{TV}$ 쪽에서 카메라를 이용한 동작 인식을 이용하는 방법을 고려 할 수 있다.

\section{참고문헌}

[1] 김명경, 이귀주, "연령별 성인 여성의 체중감량 다이어트 실태와 만족도 및 관련 지식," 한국식 품영양과학회지, Vol. 35, No. 5, pp.511-672, 2006.

[2] N.A. Kane, M.C. Simmons, D. John, D.L. Thompson, D.R. Basset, "Validity of the Nike+Device During Walking and Running," International Journal of Sports Medicine, Vol. 31, No 2, pp.101-105, 2009.

[3] Nike+ GPS 앱, http://itunes.apple.com/kr/app/ nike ${ }^{+-g p s} / \mathrm{id} 387771637 ? \mathrm{mt}=8$

[4] Cardio Trainer 앱, https://market.android.com/ details?id=com.wsl.CardioTrainer

[5] Diet Planner 앱, http://appfinder.lisisoft.com/ app/399736143.html

[6] J.A. Harris, F.G. Benedict, "A biometric study of basal metabolism in man," Washington, DC: Carnegie Institute of Washington, 1919.

[7] http://en.wikipedia.org/wiki/Harris-Benedict_ equation

[8] 이민석, "실측 데이터 기반 모션센서 에뮬레이터 의 개발," 대한임베디드공학회논문지, Vol. 6, No. 2, pp.68-75, 2011.

[9] B.E. Ainsworth, W.L. Haskell, A.S. Leon, D.R. Jacobs, H.J. Montoye, J.F. Sallis, R.S. Paffenbarger, "Compendium of Physical Activities: Classification of Energy Cost of Human Physical Activities." Medicine and Science in Sports and Activities, Vol. 25, No. 1, pp.71-80, 1993.

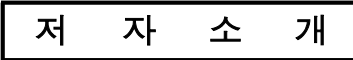

이 민 석

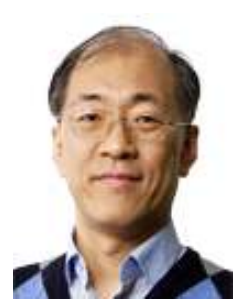

1999년 2002년 (주)팜팜테크 CTO, 1995년 현재 한성대학교 컴퓨터공학과 교 수.

관심분야: 임베디드 시스템 및 소프트웨어, 스마트폰 플랫폼, 멀티미디어 파일 시스템, 공개 소스 소프트웨어

Email : minsuk@hansung.ac.kr

\section{이 재 원}

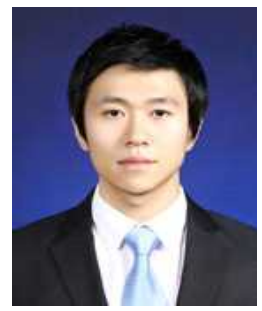

2012년 한성대학교 컴퓨 터공학과 학사.

2011년 (주) 세븐코아 연구원.

2012년 현재 LG전자 $\mathrm{MC}$ 연구소 연구원.

관심분야: 스마트폰 플랫폼, 임베디드 시스 템

Email : jaewon87@naver.com 